\title{
nature
}

Vol 439 | Issue no. 7072 | 5 January 2006

\section{No new start at Los Alamos}

\section{A fresh contract for the management of the New Mexico nuclear-weapons laboratory offers it little prospect of a happy and prosperous new year.}

\begin{abstract}
ust before Christmas, an epic struggle for management control of the United States' most venerable nuclear-weapons laboratory came to a close. The result, rather to the surprise of many observers, was that the University of California will retain the management contract to run the Los Alamos laboratory (see page 8), in partnership with the engineering group Bechtel and two other private corporations.

This means that control of the New Mexico laboratory will edge towards the private sector. But the more radical option of passing it on to fresh management under a rival consortium led by the University of Texas has been rejected. Once, this news would have led to celebrations among the 8,000 or so University of California staff at Los Alamos. But their mood is instead forlorn. Staff pensions and other benefits are not guaranteed under the new arrangement, and recent actions by the University of California have eroded goodwill.

The process by which the Department of Energy awarded the contract has been murky, even by the usual standards of such exercises. Few believe that the department's grey-suited administrators really made an independent choice. Rather, the process was characterized by delays and heavyweight political lobbying from Senator Pete Domenici (Republican, New Mexico), among others. That's par for the course, as the 'management crisis' at Los Alamos has always been more about Washington politics than about actual administrative issues at the lab.

Ever since Wen Ho Lee was accused of espionage at the lab in 1999 (he was later acquitted of major charges and convicted of minor regulatory infringements), a group in Congress led by Joe Barton (Republican, Texas) has relentlessly sought to impugn the laboratory's staff and its management by the University of California. The campaign echoes previous efforts to bring Los Alamos scientists under tighter administrative, and perhaps military, control. Its proponents have overplayed security issues at the laboratory and implied that senior scientists there cannot be trusted, either in administration or security. They have issued a stream of overblown
\end{abstract}

rhetoric, leading to the brief and unfortunate appointment of Pete Nanos, a former naval officer, to run the laboratory, as well as to last year's tendering process.

The University of California has been contracted to run the laboratory since 1943, and it traditionally did so for a nominal fee, kept its hands off day-to-day management, and offered scientists and engineers there the opportunities that came with affiliation to one of the world's best public university systems.

By seeking to blame the university for the lab's difficulties, some in Washington have sought to deflect attention from their own culpability, which is considerable. In reality, the laboratory is controlled not by its contractor, but by the byzantine Department of Energy and its overseers in several congressional committees. Because these committees are happy to make rules but are "By seeking to blame the university for the lab's difficulties, some in Washington have sought to deflect attention from their own culpability." incapable of constraining expenditure, the nudear-weapons labs have lately been given more money and much more oversight and regulation. As a result, they became steadily less efficient and productive.

The University of California and its partners, meanwhile, must pick up the pieces at Los Alamos and start afresh. Their appointment of Michael Anastasio, director of the rival Lawrence Livermore laboratory, to run Los Alamos has not exactly thrilled the existing staff there, given the historical rivalry between the two institutions. And staff briefings just before Christmas shed little light on what the new management team is actually going to do.

Los Alamos retains expertise in areas such as physics, materials, computer science, neutron scattering and mathematics. The key to its continued relevance is close liaison between its researchers in these fields and the academic community outside. But given the constraints under which they must operate, the new contractors will be hard-pressed to make the laboratory thrive.

\section{Developing resistance}

\section{A study of opposition to a vaccine for children shows how the public can lose faith in science.}

$\uparrow$ thand ostradamus we are not, but a safe prediction for 2006 is that initiatives promoting public engagement in science and technology policy-making will proliferate. There will, of course, be devils in the details, and critical assessments will be required. But Nature, having consistently championed public engagement, can nevertheless only welcome its development.
But there are times when no amount of explanation and consultation can counter the resistance of some sectors of the public, often representing a strong current in society, to the most carefully crafted science-based advice. Because the stakes for people's quality of life, economic development and the rights of individuals can be high, governments and the rest of us need to understand how and why such resistance to science develops.

Studies by social scientists have a major role to play in providing an understanding of how such resistance develops. A notable example is British research led by Melissa Leach at the University of Sussex into strong resistance by parents to their children receiving a freely available vaccination against measles, mumps and rubella 